«Obiurgatio siue exprobratio » : le discours de Scipion aux soldats rebelles chez Tite-Live

\title{
Benoît Sans
}

\section{(2) OpenEdition}

1 Journals

Édition électronique

URL : http://journals.openedition.org/rhetorique/326

DOI : $10.4000 /$ rhetorique.326

ISSN : 2270-6909

Éditeur

UGA Éditions/Université Grenoble Alpes

Édition imprimée

ISBN : 978-2-84310-274-5

Référence électronique

Benoît Sans, « «Obiurgatio siue exprobratio » : le discours de Scipion aux soldats rebelles chez Tite-Live ", Exercices de rhétorique [En ligne], 3 | 2014, mis en ligne le 16 juin 2014, consulté le 12 septembre 2020. URL : http://journals.openedition.org/rhetorique/326 ; DOI : https://doi.org/10.4000/rhetorique. 326

Ce document a été généré automatiquement le 12 septembre 2020.

\section{(c) (1) (9)}

Les contenus de la revue Exercices de rhétorique sont mis à disposition selon les termes de la Licence Creative Commons Attribution - Pas d'Utilisation Commerciale - Partage dans les Mêmes Conditions 4.0 International. 


\title{
"Obiurgatio siue exprobratio »: le discours de Scipion aux soldats rebelles chez Tite-Live
}

\author{
Benoît Sans
}

1 La formule de notre titre pose le problème que nous traiterons ici. Il s'agit de savoir de quel genre ou plutôt de quel type de discours relève précisément celui de Scipion à ses soldats rebelles: ou bien une réprimande ou objurgation (« obiurgatio»), ou bien des reproches sévères, voire une condamnation sans appel (une "exprobratio»). Le fait même qu'un commentateur ancien puisse hésiter entre les deux termes est significatif, et renvoie comme nous allons le voir à la structure du discours. En apparence, Scipion lui aussi hésite entre ces deux directions, entre les deux tons à adopter, l'un clément et l'autre sévère.

2 En 206 avant J.-C., Scipion a remporté une série de succès (Carthagène, Baecula, Ilipa) qui lui ont permis de reprendre la majeure partie de l'Espagne aux Carthaginois et de rallier à sa cause nombre de populations indigènes. Mais la rumeur se répand que Scipion est gravement malade, occasion dont profitent les soldats cantonnés à Sucro pour se mutiner : ils chassent leurs officiers et donnent les insignes du commandement à leurs meneurs. L'épisode, premier du genre, nous est rapporté par Polybe et Tite-Live, et n'a pas manqué d'intriguer les historiens modernes ${ }^{1}$. Toutefois, nous ne connaîtrons sans doute jamais les véritables raisons de ce mouvement de grogne, tant les deux récits, teintés de préoccupations éthiques et politiques, restent opaques à l'analyse : d'après Polybe et Tite-Live, les soldats réclament le versement de leur solde, mais leur insubordination est surtout due à une trop longue période d'oisiveté ; les deux auteurs leur prêtent également l'intention de s'allier aux princes espagnols qui font sécession au même moment. Scipion se trouve dans une position délicate et inédite pour lui : il doit faire preuve de fermeté pour réprimer la révolte, mais en même temps éviter de se faire détester par une partie importante de ses troupes et les faire rentrer dans le rang. En bon stratège, le jeune commandant parvient rapidement à redresser la situation en tendant un piège aux mutins : il les invite à venir recouvrer leur solde à Carthagène, où 
il a établi ses quartiers, et fait ainsi croire à un versement rapide. Lorsque les meneurs de l'insurrection se présentent à l'invitation, il les fait secrètement capturer sous le couvert de l'hospitalité. Pour donner aux autres rebelles l'impression d'être sans défense, il monte également une fausse expédition contre les séparatistes espagnols. Après l'arrivée du reste des troupes séditieuses à Carthagène, au moment opportun, les régiments fidèles à Scipion, commandés par Silanus, font demi-tour et encerclent les dissidents sur la place centrale de la cité. Scipion apparaît alors en pleine forme, ce qui crée la stupeur parmi les auditeurs, et, après un bref mais pesant silence, adresse un discours aux insurgés depuis la tribune. L'allocution achevée, les meneurs sont suppliciés sous les yeux du public : celui-ci assiste avec effroi et impuissance à une mise en scène atroce et décrite en détails par Polybe et Tite-Live. Les soldats de Sucro prêtent à nouveau le serment de fidélité qu'ils avaient rompu et reçoivent leur solde. L'ordre est rétabli : fin de l'épisode.

3 Le discours fourni par Tite-Live est très différent de celui de son homologue grec et, ainsi remis dans son contexte peu banal, s'avère difficile à appréhender, en particulier lorsque l'on tente de le raccrocher à un genre particulier: relève-t-il plutôt du délibératif, du judiciaire, de l'épidictique ou, comme souvent, d'un savant mélange ? La théorie aristotélicienne des genres, développée dans la Rhétorique, les traités de Cicéron ou de Quintilien, qui ont essentiellement en ligne de mire le discours au tribunal ou à l'assemblée, se révèlent trop imprécis pour rendre compte des productions oratoires riches et variées que l'on trouve chez les historiens et qui répondent à des situations spécifiques. Au sein des discours attribués par les historiens aux protagonistes de leur récit en différentes circonstances, on observe parfois de troublantes récurrences et des régularités, qui dessinent des types, et l'on sait aussi que certains d'entre eux ont remporté un franc succès ${ }^{2}$. Le discours de Scipion serait-il de ceux-là ? correspond-il à un sous-genre ou à type précis? est-ce une condamnation plus ou moins sévère et univoque, ou bien une tentative de réconciliation plus ou moins adroite ? existe-t-il des parallèles? Ceux qui, surtout aux $\mathrm{XVI}^{\mathrm{e}}$ et $\mathrm{XVII}^{\mathrm{e}}$ siècles, ont entrepris d'étudier et de classifier les innombrables discours transmis par les historiens anciens ont été les premiers - et parfois encore les seuls - à s'intéresser à la valeur littéraire et rhétorique de ces discours, et à se pencher sur les questions qui viennent d'être posées. Ils ont tenté d'y répondre en s'appuyant sur les traités antiques, mais aussi en les raffinant et en les complétant pour pallier leurs lacunes. Je voudrais ici tirer profit de ces commentaires pour comprendre et démêler le discours de Tite-Live. Il faut tout d'abord relire attentivement l'intervention de Scipion en s'aidant des analyses auxquelles j'ai fait référence : je me servirai ici des conciones de Marco Antonio Ferrazzi, Johannes Tesmar, Melchior Junius et de Joachim Perion ${ }^{3}$; je les rapprocherai ensuite des réflexions plus générales et théoriques sur les genres de discours que proposent les traités systématiques de Nicolas Caussin, Gérard Pelletier et Gerhard Vossius ${ }^{4}$; je tâcherai enfin de mettre en lumière les originalités autant que les régularités du discours de Scipion en explorant quelques cas parallèles qu'il est possible de dénicher grâce aux qualifications proposées par les auteurs précités.

\section{Le discours chez Polybe}

4 Avant de plonger dans la lecture du discours de Scipion chez Tite-Live, il convient de s'arrêter brièvement sur celui qui est transmis par Polybe (XI, 25-30) : la comparaison 
permettra de révéler certaines des spécificités de chaque texte et révèle à quel point un même événement, un même discours, peut recevoir des écritures différentes selon les auteurs ; sans doute aussi, en fonction d'objectifs différents.

Le discours chez Polybe est bref et son plan est assez clair. L'allocution est d'abord transmise en style indirect et s'ouvre sur un exorde un peu sec: Scipion interroge les auditeurs sur les raisons de leur geste et montre son étonnement. Cette courte introduction est immédiatement suivie par une annonce du plan ou partitio. Selon le général romain, il y a trois raisons qui peuvent pousser des soldats à se rebeller : avoir grief contre leur supérieur, être mécontents de la situation globale ou concevoir de plus grandes espérances ailleurs et autrement. Dans l'argumentation du discours, le Romain s'emploie alors à réfuter l'existence d'un de ces trois motifs dans le cas considéré.

6 Premièrement, il détourne le problème du non-versement de la solde et transfère la responsabilité en dénonçant une disproportion des moyens; par transitivité, l'agression contre Scipion est reportée sur la patrie, ce qui rend l'action indigne. Scipion utilise le lieu a comparatione (un parallèle) pour rendre ses soldats moins dignes d'excuse que de vulgaires mercenaires, et avec une similitudo (analogie), il les compare même à des parricides. Il ne peut encore imaginer que ses hommes puissent avoir le sentiment d'avoir été traités de manière injuste et refuse tout simplement de discuter ce point, en feignant de tirer argument du silence de l'assistance. Le deuxième motif est exclusivement abordé sous la forme de questions rhétoriques, qui sont un appel à l'évidence : pour Scipion, la situation de Rome n'a jamais été meilleure depuis le début de la guerre. Enfin, le troisième point est plus pragmatique et développe le lieu de l'utile : Scipion suggère que les Espagnols sont des alliés peu fiables.

7 Le Romain développe ensuite un argument a comparatione en prétendant que même avec l'aide des Espagnols, ils n'auraient pu l'emporter face lui, et il dénigre davantage encore les compétences des chefs de l'insurrection. Jusqu'ici donc, l'argumentation est assez simple, voire réductrice : toute rébellion doit avoir un des trois motifs énumérés ( $\mathrm{p} \Leftrightarrow>\mathrm{q} \vee \mathrm{r} \vee \mathrm{s}$ ); comme les soldats de Sucro n'en ont aucun, leur mouvement est illégitime. Se produit alors un revirement inattendu: Scipion veut comprendre ses hommes et prendre leur défense en fournissant une explication à la révolte, sans pour autant l'excuser. Il se sert d'une similitudo entre l'agitation de la mer et celle de la foule pour charger les meneurs et déresponsabiliser la masse des soldats. Il annonce ensuite sa sentence.

8 L'argumentation du discours comporte donc deux parties bien séparées, l'une qui se veut une démonstration accablante et l'autre qui tente d'arrondir les angles. Le discours a souvent paru abrupt et peu convaincant aux yeux des modernes ${ }^{5}$. Du point de vue de l'ethos, Scipion apparaît froid et sévère, même s'il manifeste une volonté de comprendre l'inacceptable. Au niveau des émotions, les choses ne sont pas très claires : Scipion exprime de la colère, de l'indignation peut-être ; il veut en tout cas susciter la honte et après avoir fait craindre le pire, apporte le soulagement sous la forme d'une solution séduisante. En fait, ce que nous offre Polybe, n'est pas tant un moment de rhétorique qu'une réflexion stratégique, politique ${ }^{6}$ et philosophique sur les causes des crises internes et la façon de les gérer; le discours n'est qu'un prétexte. Si Polybe ne déroge pas à une tradition déjà bien ancrée dans l'historiographie ancienne, il s'y intéresse fort peu, et préfère louer l'action de Scipion dans son ensemble. L'analogie entre les crises politiques et les agressions du corps qui, un peu plus tôt ${ }^{7}$, met en 
évidence le caractère délicat de la situation et accompagne la réaction de Scipion, donne le ton et annonce une intention didactique bien connue chez l'historien grec.

\section{Le discours chez Tite-Live : analyse des séquences, de l'exorde à la péroraison}

Chez Tite-Live (XXVIII, 27-29), le discours de Scipion est d'une tout autre envergure, tant par sa valeur littéraire que par son ampleur et sa complexité. J'opposerai ici les analyses de Ferrazzi, Tesmar et Perion à celle de Junius ${ }^{8}$. Les premiers ont une approche linéaire et analytique qui consiste à découper le discours et à identifier les arguments pas à pas; le second emploie une méthode plus synthétique qui consiste à remplir les cases d'une grille préétablie à l'aide des énoncés du discours. Chacune de ces lectures offre des clés de compréhension intéressantes, d'autant que Ferrazzi a clairement Tesmar sous la main. Tous les auteurs sont, à quelques détails près, en accord sur un plan en trois parties : le discours de Tite-Live est ici pourvu d'un véritable exorde, d'une argumentation et d'une péroraison. L'absence de narration proprement dite peut surprendre, j'y reviendrai bien plus loin, lorsque nous serons enfin en mesure de déterminer de quel genre ou type de discours relève celui de Scipion. Pour l'instant, dans cette partie analytique, je vais me contenter de suivre l'ordre du texte, en mettant d'abord sous les yeux du lecteur le latin de Tite-Live et sa traduction française par Charles Nisard. Pour l'essentiel, je reprends l'analyse ou découpage de Ferrazzi en trois parties: exorde, partie argumentative avec cinq arguments, "conclusion» ou péroraison, chaque argument étant lui-même identifié par un lieu principal.

\section{7, 1-4 (exorde)}

C'est l'exorde, selon tous les commentateurs ${ }^{9}$ :

XXVIII, 27, 1 Alors, le héraut ayant fait faire silence, Scipion commença ainsi : «Jamais je n'aurais cru que les mots me manqueraient pour m'adresser à mon armée, 2 non que je me fusse jamais exercé à la parole plus qu'à l'action, mais parce que, resté dans les camps presque depuis l'enfance, j'avais l'habitude du caractère des soldats. 3 À vous, pourtant, comment vous parler? Ni les idées, ni les mots ne m'en fournissent le moyen; car je ne sais pas même par quel nom je dois m'adresser à vous. 4 Citoyens, vous qui vous êtes séparés de votre patrie ? Soldats, vous qui avez nié l'autorité militaire et le droit d'auspices, rompu un serment religieux ? Ennemis ? Pour la stature, les traits, les vêtements, la tenue, je reconnais des concitoyens; dans les actes, les paroles, les desseins, je vois des sentiments d'ennemis.

XXVIII, 27, 1 Tum silentio per praeconem facto ita coepit: "numquam mihi defuturam orationem qua exercitum meum adloquerer credidi, 2 non quo verba umquam potius quam res exercuerim, sed quia prope a pueritia in castris habitus adsueram militaribus ingeniis; 3 apud vos quem ad modum loquar nec consilium nec oratio suppeditat, quos ne quo nomine quidem appellare debeam scio. 4 Cives? qui a patria vestra descistis. An milites? qui imperium auspiciumque abnuistis, sacramenti religionem rupistis. Hostes? corpora, ora, vestitum, habitum civium adgnosco ; facta, dicta, consilia, animos hostium video.

11 Scipion affiche d'abord son étonnement et son incompréhension face à une situation inédite et inimaginable pour lui («Jamais je n'aurais», «nunquam... unquam»). Il justifie ce sentiment en insistant, non sur ses capacités, mais sur le lien qui l'unit à ses soldats : ce faisant, il manifeste sa «majesté » ou autorité et supériorité comme chef, 
c'est-à-dire sa maiestas, qui apparaîtra plus clairement à divers endroits du discours, et il cherche à raviver l'amitié ou beneuolentia de ses hommes envers lui. Il montre qu'il est un des leurs, qu'il a consacré son existence à la vie militaire et qu'il est leur chef. Mais il ne trouve plus les mots pour s'adresser à ses compagnons d'armes et manifeste son désarroi par une série d'apostrophes et de questions rhétoriques rythmées en gradation ${ }^{10}$ ("Ni... ni... », «nec... nec... ne... quidem »), où il refuse d'accorder une série de titres à ses interlocuteurs. Il précise à chaque fois les critères définitionnels, les qualités requises du bon soldat, et dresse ainsi le portrait d'une armée idéale qui n'est pas celle qu'il a devant lui.

\section{$27,5-6$}

Thèse, ou proposition; pour Ferrazzi, c'est là le premier argument, tiré du lieu $a$ comparatione :

5 En quoi, en effet, vous êtes-vous distingués des Ilergètes et des Lacetani dans vos souhaits ou dans vos espoirs? Eux, cependant, ce sont Mandonius et Indibilis, des hommes d'une noblesse royale, qu'ils ont suivis dans leur folie; vous, vous avez déféré le droit d'auspices et l'autorité militaire à Atrius l'Ombrien et à Albius de Calès. 6 Dites que vous n'avez pas tous fait cela ou voulu le faire, soldats, que peu d'entre vous ont été atteints d'une telle folie, d'une telle démence; je croirai volontiers ceux qui le diront: car telles sont les fautes commises que, si elles s'étaient répandues dans toute l'armée, on ne pourrait les expier sans de lourdes expiations.

5 Quid enim vos, nisi quod Ilergetes et Lacetani, aut optastis aliud aut sperastis? et illi tamen Mandonium atque Indibilem, regiae nobilitatis viros, duces furoris secuti sunt; vos auspicium et imperium ad Vmbrum Atrium et Calenum Albium detulistis. 6 Negate vos id omnes fecisse aut factum voluisse, milites; paucorum eum furorem atque amentiam esse; libenter credam negantibus; nec enim ea sunt commissa quae, volgata in omnem exercitum, sine piaculis ingentibus expiari possint.

Dans une question cinglante $(27,5)$, le général romain annonce son intention de comprendre les intentions des rebelles, mais semble tenir pour acquis qu'ils espéraient rejoindre la sécession des Espagnols. Il oppose les deux mouvements et se sert de la défection des indigènes pour créer un argument a comparatione $e^{11}$ et dénigrer l'insurrection des soldats romains: ceux-ci se sont choisi des meneurs bien moins nobles. Si, pour Ferrazzi ou Tesmar, la partie argumentative ou contentio commence déjà ici, c'est que Scipion prouve que les insurgés ont «agi en ennemis » ("hostiliter egisse ", Tesmar). Il s'agit surtout de montrer que l'action est grave mais peu réfléchie, ainsi que de transférer la responsabilité sur quelques-uns, qui ont usurpé des pouvoirs exorbitants. Notons que ces meneurs sont qualifiés de chefs non de la rébellion, mais de la folie, "duces furoris»: Scipion introduit l'idée cruciale d'une folie ou furor. Le paragraphe suivant est particulièrement audacieux et original: Scipion dit à ses hommes ce qu'il veut entendre. On peut y voir une sorte de thèse ou propositio, ou tout $\mathrm{du}$ moins une "prolepse " argumentative (Tesmar) c'est-à-dire la réponse à une objection, car on y trouve résumée la thèse défendue par l'orateur: la révolte est le fruit d'une folie (furor, amentia) passagère, agitée par quelques-uns, mais elle peut encore être expiée par un châtiment. Scipion se servira de ce lexique religieux tout au long du discours. 


\section{$27,7-11$}

Pour Ferrazzi, il s'agit du deuxième argument, tiré du lieu ab adjunctis (suae integritatis) :

7 C'est malgré moi que je touche à ces sortes de blessures ; mais, sans y toucher et y retoucher, on ne peut les guérir. 8 En vérité, une fois les Carthaginois chassés d'Espagne, je croyais qu'il n'y avait point d'endroit dans la province entière, point de gens pour haïr ma vie : telle avait été ma conduite non seulement envers les alliés, mais envers les ennemis. 9 Et voici que dans mon camp - combien mon attente m'a trompé ! - le bruit de ma mort a été non seulement bien accueilli, mais attendu. 10 Ce n'est pas que je veuille étendre ce crime à tous - vraiment, si je croyais que toute mon armée a souhaité ma mort, ici, tout de suite, sous vos yeux, je mourrais; il ne me plairait pas de mener une vie odieuse à mes concitoyens et à mes soldats - ; 11 mais toute multitude, comme, par nature, la mer, est par ellemême immobile ; les vents et les brises l'agitent ; ainsi le calme comme les tempêtes sont en vous, le motif, l'origine de toute folie sont dans les agitateurs; vous, c'est la contagion qui vous égare.

7 Invitus ea tamquam volnera attingo; sed nisi tacta tractataque sanari non possunt. 8 Equidem pulsis Hispania Carthaginiensibus nullum locum tota provincia, nullos homines credebam esse ubi vita invisa esset mea; sic me non solum adversus socios gesseram, sed etiam adversus hostes. 9 In castris en meis - quantum opinio fefellit - fama mortis meae non accepta solum, sed etiam exspectata est. 10 Non quod ego volgari facinus per omnes velim - equidem, si totum exercitum meum mortem mihi optasse crederem, hic statim ante oculos vestros morerer, nec me vita iuvaret invisa civibus et militibus meis. 11 Sed multitudo omnis sicut natura maris per se inmobilis est, at venti et aurae cient; ita aut tranquillum aut procellae in vobis sunt; et causa atque origo omnis furoris penes auctores est, vos contagione insanistis,

15 L'image médicale ${ }^{12}$ qui ouvre ce passage annonce un retour sur les événements et une section narrative. Ce moment douloureux est justifié par une volonté de dépassement, il est présenté comme une étape indispensable pour une fin positive, la guérison d'un mal. Avec ce rappel s'ouvre la deuxième partie de l'argumentation de Scipion, qui exploite le lieu des circonstances de la personne (la sienne - « ab adiunctis », Ferrazzi) et fustige l'ingratitude des soldats (Tesmar). Le passage est assez court : il s'agit en fait d'un recadrage des événements à travers le point de vue de Scipion, qui montre son innocence et se fait passer pour la victime de sa propre naïveté. Alors que la situation était favorable et que le général se comportait avec bienveillance, idées que l'on retrouve à un autre endroit dans le discours de Polybe, les soldats ont agi ingrate et immerito : sans gratitude, sans que Scipion ait rien fait pour mériter une telle attitude. Scipion utilise, ici aussi, un argument a comparatione avec les alliés et les ennemis pour souligner le caractère inattendu de l'hostilité des soldats romains à son égard. Il se dit trompé et préférerait mourir plutôt que de commander une armée qui ne veut plus de lui. Pourtant, il est toujours là, ce qui apparaît comme une sorte de contradiction ; il ne pense donc pas qu'un ressentiment profond soit à l'origine de l'insurrection. C'est ici qu'apparaît $(27,11)$ l'image ou similitudo avec la mer, par laquelle Scipion tente d'excuser ses hommes, mais aussi de reporter à nouveau la responsabilité sur un petit nombre de coupables, qui sont la véritable cause du mal qui s'est ensuite étendu à tous. Scipion répète sa thèse comme un refrain : "c'est la contagion qui vous égare ", "uos contagione insanistis ». Il poursuit en précisant, dans un passage très rythmé, que les soldats ne mesurent pas la gravité de leurs crimes et surtout les valeurs qu'ils ont bafouées : famille, patrie, dieux, serments, discipline militaire et la majesté ou maiestas 
elle-même. Cette ignorance manifeste, selon lui, est comme une preuve de leur « démence » (« amentia»).

\section{$27,12-16$}

Pour Ferrazzi, c'est le troisième argument, tiré du lieu ab effectis :

12 Aujourd'hui même, vous ne savez pas, je crois, jusqu'où vous êtes allés dans la démence, quel forfait vous avez osé contre moi, contre votre patrie, vos parents et vos enfants, contre les dieux, témoins du serment, contre les auspices sous lesquels vous servez, contre les usages de l'armée et la discipline ancestrale, contre la majesté du commandement suprême. 13 Sur moi, je ne dirai rien : vous avez mis sans doute plus de légèreté que d'espoir à croire à ma mort ; sans doute enfin suis-je tel, que le fait de voir mon armée lasse d'être commandée par moi ne doive pas étonner du tout. Mais la patrie, que vous avait-elle fait pour que vous vous alliiez à Mandonius et à Indibilis afin de la trahir ? 14 Que vous avait fait le peuple romain, pour que vous donniez le commandement, enlevé à des tribuns nommés par un vote de ce peuple, à de simples particuliers; pour que, non contents de les avoir pour tribuns, vous donniez les faisceaux de votre général à des gens qui n'avaient jamais eu un esclave à commander, vous, une armée romaine ? 15 Au prétoire, Albius et Atrius ont dressé leur tente ; la trompette a sonné devant eux ; on leur a demandé le mot d'ordre; ils se sont assis sur le tribunal de Publius Scipion; le licteur leur a servi d'appariteur; dans l'espace dégagé par lui, ils se sont avancés; on a porté devant eux les faisceaux avec les haches. 16 Des pluies de pierres, des coups de foudre, la naissance de monstres vous semblent des prodiges : votre conduite est un prodige tel qu'aucune victime, aucune prière ne peuvent l'expier, sans verser le sang des hommes qui ont osé un si grand forfait.

12 qui mihi ne hodie quidem scire videmini quo amentiae progressi sitis, quid facinoris in me, quid in patriam parentesque ac liberos vestros, quid in deos sacramenti testes, quid adversus auspicia sub quibus militatis, quid adversus morem militiae disciplinamque maiorum, quid adversus summi imperii maiestatem ausi sitis. 13 De me ipso taceo-temere potius quam avide credideritis, is denique ego sim, cuius imperii taedere exercitum minime mirandum sit : patria quid de vobis meruerat, quam cum Mandonio et Indibili consociando consilia prodebatis? 14 quid populus Romanus, cum imperium ablatum ab tribunis suffragio populi creatis ad homines privatos detulistis, cum eo ipso non contenti si pro tribunis illos haberetis, fasces imperatoris vestri ad eos quibus servus cui imperarent numquam fuerat, Romanus exercitus detulistis? 15 In praetorio tetenderunt Albius et Atrius, classicum apud eos cecinit, signum ab iis petitum est, sederunt in tribunali P. Scipionis, lictor apparuit, summoto incesserunt, fasces cum securibus praelati sunt. 16 Lapides pluere et fulmina iaci de caelo et insuetos fetus animalia edere vos portenta esse putatis: hoc est portentum quod nullis hostiis, nullis supplicationibus sine sanguine eorum qui tantum ausi facinus sunt expiari possit.

Ici, les commentateurs sont unanimes pour relever un nouveau mouvement dans l'argumentation ${ }^{13}$, qui exploite le lieu des effets, ab effectis. Jusqu'au paragraphe 27, 16, Scipion s'attache à justifier ce qu'il soutient dans le paragraphe 12 et à montrer en quoi les rebelles ont agi de manière injuste : ils ont commis un crime ou facinus bafouant toute une série de symboles (pour paraphraser Tesmar : «injustitiam arguit ex objectis violatis »). L'orateur fait d'abord une concession aux auditeurs, il admet qu'on peut se lasser de lui et s'ouvre ainsi la possibilité de traiter un autre aspect de l'insurrection. Ce procédé, qui réapparaîtra dans la suite du discours, accompagne l'argumentation et témoigne de la prise en compte de la psychologie supposée du public. Ensuite («Mais la patrie...»), pour montrer la gravité du crime, Scipion utilise l'amplification par exaggeratio (Perion), c'est-à-dire ici par accumulation. Il assène de nouvelles questions à 
ses interlocuteurs et énumère, dans une série rythmée annoncée par le paragraphe 12 (" contre moi, contre votre patrie »), toutes les bravades de ses hommes. Il s'attèle tout particulièrement à rabaisser les meneurs du mouvement, qui sont d'illustres inconnus, d'origine modeste et incompétents : la comparaison négative avec les chefs espagnols, l'argument a comparatione (a fortiori) nourrissent une argumentation ad hominem. L'acte commis est une trahison, mais aussi un sacrilège car il a porté atteinte à des symboles sacrés. On retrouve donc dans ce passage un condensé des lieux que Scipion a déjà utilisés: le locus a comparatione (avec les princes espagnols); le locus ab adiunctis (de nouveau, circonstances de la personne : les symboles du général en chef, faisceaux et haches, bafoués dans la foulée de la défection); enfin la comparatio avec un «portentum » ou prodige qu'il faut expier.

\section{$28,1-7$}

Pour Ferrazzi, quatrième argument, tiré du lieu a comparatione imparium :

28, 1 Pour moi, cependant, quoique le crime ne raisonne jamais, je voudrais - autant que c'est possible pour un acte sacrilège, savoir quels ont été votre idée, votre projet. 2 À Regium, autrefois, une légion, envoyée en garnison, après avoir égorgé criminellement les notables de la cité, occupa dix ans cette ville opulente ; 3 à cause de ce forfait, la légion entière, ses quatre mille hommes, furent sur le forum, à Rome, frappés de la hache. 4 Mais d'abord, ces gens-là suivirent non un Atrius l'Ombrien, mi-soldat, mi-cantinier, général dont le nom même est de mauvais augure, mais Decius Vibellius, tribun des soldats ; ils ne se joignirent pas à Pyrrhus, ni aux Samnites ou aux Lucains, ennemis du peuple romain; 5 vous, vous avez communiqué vos plans à Mandonius et à Indibilis, vous avez projeté de mettre en commun avec eux vos armes. 6 Ces gens-là, comme les Campaniens à Capoue (enlevée aux Toscans, ses anciens habitants) comme les Mamertins à Messine en Sicile, se proposaient de garder toujours Regium comme résidence, et de ne harceler d'offensives ni le peuple romain, ni les alliés du peuple romain : 7 vous proposez-vous, vous, de garder Sucron comme domicile? Si moi, votre général, quittant cette province, ma mission achevée, je vous y laissais, vous devriez implorer le secours des dieux et des hommes parce que vous ne retourneriez pas auprès de vos femmes et de vos enfants.

28, 1 Atque ego, quamquam nullum scelus rationem habet, tamen, ut in re nefaria, quae mens, quod consilium vestrum fuerit scire velim. 2 Regium quondam in praesidium missa legio interfectis per scelus principibus civitatis urbem opulentam per decem annos tenuit ; 3 propter quod facinus tota legio, milia hominum quattuor, in foro Romae securi percussi sunt. 4 Sed illi primum non Atrium Vmbrum semilixam, nominis etiam abominandi ducem, sed D. Vibellium tribunum militum secuti sunt, nec cum Pyrrho nec cum Samnitibus aut Lucanis, hostibus populi Romani, se coniunxerunt; 5 vos cum Mandonio et Indibili et consilia communicastis et arma consociaturi fuistis. 6 Illi, sicut Campani Capuam Tuscis veteribus cultoribus ademptam, Mamertini in Sicilia Messanam, sic Regium habituri perpetuam sedem erant, nec populum Romanum nec socios populi Romani ultro lacessituri bello: 7 Sucronemne vos domicilium habituri eratis? Vbi si vos decedens confecta provincia imperator relinquerem, deum hominumque fidem implorare debebatis, quod non rediretis ad coniuges liberosque vestros.

19 Après avoir envisagé les faits et leur qualification sous l'angle des valeurs qui n'ont pas été respectées, ici à partir de ce chapitre 28 , Scipion entre dans des considérations plus pragmatiques ou pratiques ${ }^{14}$. Même s'il ne peut admettre que l'insurrection ait une raison valable ( $\$ 1$, «quoique le crime ne raisonne jamais ", "quamquam nullum scelus rationem habet»), il concède néanmoins qu'elle puisse avoir un motif, et plus précisément une finalité ou « cause finale » (« causa finalis », Ferrazzi). Mais il ne va pas 
tant insister sur ce qui motive le mouvement de révolte que, "par énumération » (Tesmar), sur ce qui lui fait obstacle (« enumeratione causarum impedientium », Tesmar) : il veut montrer que l'insurrection est à la fois inutile, car elle n'est pas profitable aux insurgés, mais aussi stupide, car elle n'avait que peu de chances d'aboutir et de perdurer (Tesmar : «il prouve que cela a été fait de façon stupide, en repoussant la finalité de l'utile», "stulte fecisse probat remotione finis utilis»). Pour tenter de déterminer la finalité de la mutinerie, Scipion use d'une triple comparatio imparium, un " parallèle entre choses inégales ", qui constitue ce quatrième argument selon Ferrazzi. L'orateur utilise d'abord un exemple (historique) dissemblable, à savoir l'exemplum dissimile de la sécession de la légion de Regium, pour montrer la différence et, à nouveau, la gravité, de la révolte de Sucro. Puis il convoque d'autres précédents pour induire que l'objectif d'un tel acte est généralement de trouver une nouvelle résidence, un nouveau foyer. Mais Scipion pousse alors cette logique jusqu'à l'absurde et montre qu'elle est incompatible avec le fait que les soldats possèdent déjà un foyer, qu'ils sont censés vouloir retrouver, et dont ils se priveraient ainsi définitivement.

\section{8,8 à 29,2}

Pour Ferrazzi, cinquième argument (tiré du lieu a causa finali), lui-même subdivisé en cinq arguments ${ }^{15}$, qui prouvent l'absurdité du projet des rebelles (dementia consilii) :

8 Admettons cependant qu'eux aussi, vous les ayez chassés de vos cœurs, comme votre patrie et moi-même; c'est la démarche de votre dessein, criminel, non insensé au dernier point, que je veux suivre. 9 Moi vivant, et l'armée (vous exceptés) intacte, avec laquelle, par moi, Carthagène a été prise en un seul jour, avec laquelle quatre généraux, quatre armées carthaginoises ont été enfoncées, mises en fuite, chassées d'Espagne, vous - huit mille hommes dont aucun ne vaut, sans doute, Albius et Atrius, à qui vous vous étiez subordonnés - vous prétendiez arracher la province d'Espagne au peuple romain ? 10 J'écarte, je mets à part mon nom ; admettons que, sauf en croyant trop facilement à ma mort, vous ne m'avez outragé en rien. 11 Eh quoi ? si je mourais, avec moi l'État expirerait, avec moi tomberait l'empire romain? Veuille Jupiter Très bon, Très grand ne pas permettre ce désastre qu'une ville fondée après avoir pris les auspices, à l'instigation des dieux eux-mêmes, pour l'éternité, ait seulement la durée de ce corps fragile et mortel ! 12 Quoique Flaminius, Paul-Émile, Gracchus, Postumius Albinus, Marcus Marcellus, Titus Quinctius Crispinus, Cneius Fulvius, les Scipions, mes aïeux, tant de généraux illustres, aient été enlevés par une seule guerre, le peuple romain est resté debout, et il le restera, même si mille autres généraux mouraient soit par le fer, soit de maladie: et mes seules funérailles auraient emporté l'État romain? 13 Vousmêmes, ici, en Espagne, quand mon père et mon oncle, vos deux généraux, eurent été tués, vous avez choisi Septimus Marcius pour vous commander contre les Carthaginois, exaltés par leur victoire récente. Et je parle comme si les Espagnes avaient dû, par ma mort, rester sans chef : 14 mais Marcus Silanus envoyé, en même temps que moi, avec les mêmes droits, le même pouvoir, mais les lieutenants Lucius Scipion, mon frère, et Caius Laelius, manqueraient-ils à venger la majesté du commandement ? 15 Est-ce votre armée qu'on pouvait comparer à notre armée, ou vos chefs à nos chefs, ou nos titres, ou nos causes? Même supérieurs sur tous ces points, porteriez-vous les armes, avec les Carthaginois, contre votre patrie, contre vos concitoyens? Voudriez-vous que l'Afrique commandât à l'Italie, Carthage à Rome? Quel tort a eu pour cela votre patrie ? 29, 1 Coriolan fut, autrefois, par une condamnation injuste, par un exil malheureux et immérité, poussé à marcher contre sa patrie ; mais sa piété pour une personne privée le détourna d'un attentat contre le peuple. 2 Vous, quel ressentiment, quelle colère vous a excités ? Votre 
solde, payée, à cause de la maladie de votre général, avec quelques jours de retard, était-ce une raison suffisante pour déclarer la guerre à votre patrie, pour abandonner le peuple romain au bénéfice des Ilergètes, pour ne rien laisser dans la religion, dans la société sans l'outrager?

8 Sed horum quoque memoriam, sicut patriae meique, eieceritis ex animis Vestris; viam consilii scelerati sed non ad ultimum dementis exsequi volo. 9 Mene vivo et cetero incolumi exercitu, cum quo ego die uno Carthaginem cepi, cum quo quattuor imperatores, quattuor exercitus Carthaginiensium fudi, fugavi, Hispania expuli, vos octo milia hominum, minoris certe omnes pretii quam Albius et Atrius sunt quibus vos subiecistis, Hispaniam provinciam populo Romano erepturi eratis? 10 Amolior et amoveo nomen meum; nihil ultra facile creditam mortem meam a vobis violatus sim : 11 quid? si ego morerer, mecum exspiratura res publica, mecum casurum imperium populi Romani erat? Ne istuc Iuppiter optimus maximus sirit, urbem auspicato deis auctoribus in aeternum conditam huic fragili et mortali corpori aequalem esse. 12 Flaminio, Paulo, Graccho, Postumio Albino, M. Marcello, T. Quinctio Crispino, Cn. Fulvio, Scipionibus meis, tot tam praeclaris imperatoribus uno bello absumptis superstes est populus Romanus, eritque mille aliis nunc ferro nunc morbo morientibus: meo unius funere elata esset res publica? 13 Vos ipsi hic in Hispania patre et patruo meo, duobus imperatoribus, interfectis Septimum Marcium ducem vobis adversus exsultantes recenti victoria Poenos delegistis. Et sic loquor tamquam sine duce Hispaniae futurae fuerint : $14 \mathrm{M}$. Silanus eodem iure, eodem imperio mecum in provinciam missus, $L$. Scipio frater meus et $C$. Laelius legati, vindices maiestatis imperii deessent? 15 Vtrum exercitus exercitui, an duces ducibus, an dignitas, an causa comparari poterat? Quibus si omnibus superiores essetis, arma contra patriam, contra cives vestros ferretis? Africam Italiae, Carthaginem urbi Romanae imperare velletis? Quam ob noxam patriae? 29, 1 Coriolanum quondam damnatio iniusta, miserum et indignum exilium ut iret ad oppugnandam patriam impulit; revocavit tamen a publico parricidio privata pietas : 2 vos qui dolor, quae ira incitavit? Stipendiumne diebus paucis imperatore aegro serius numeratum satis digna causa fuit cur patriae indiceretis bellum, cur ad Ilergetes descisceretis a populo Romano, cur nihil divinarum humanarumve rerum inviolatum vobis esset?

21 Dans une nouvelle concession qui résume les différentes parties du discours $(28,8)$, Scipion admet alors la possibilité que les insurgés n'aient plus la moindre considération pour leur chef, leur patrie et leur famille, et envisage la viabilité d'une sécession sur le plan strictement militaire. Il soutient que ce projet est voué à l'échec grâce à une autre comparatio, un parallèle entre les capacités militaires des rebelles et celles de la majorité de l'armée, puis se retire du jeu pour rappeler, à l'aide d'antécédents anciens et récents, que Rome et la maiestas du commandant survivent au-delà de leurs incarnations particulières dans l'un ou l'autre chef d'armée (28, 10-14). Poussant jusqu'au bout la folie destructrice qu'il attribue à ses hommes, Scipion imagine enfin un renversement complet $(28,15)$ : les rebelles auraient voulu la victoire de Carthage contre leur propre patrie en raison d'un tort commis par celle-ci. Tesmar considère cette attaque comme un argument à part entière, par lequel le général romain accuse ses hommes d' "impietas", de manquement à la "piété ", à tous les devoirs dus à la patrie. Le même Tesmar voit dans l'histoire de Coriolan un exemple (historique) dissemblable, un "exemplum dissimile »: à la différence de Coriolan, les rebelles ne peuvent revendiquer un tort suffisant, comme le retard dans le versement de la solde, pour expliquer une telle réaction, redéfinie dans une nouvelle série de questions rhétoriques. L'acte est gravissime, indigne et totalement disproportionné. Scipion est arrivé à son but et au terme de son argumentation: la mutinerie ne porte aucun véritable projet, aucune finalité. Elle est donc une déraison, une folie : « vous étiez fous, soldats ", "Insanitis profecto, milites ", va-t-il répéter juste après ce passage, à 29, 3 — c'est-à-dire au début de la péroraison. 


\section{9, 3-8 (péroraison)}

S'ensuit donc le mouvement final du discours :

3 Assurément, vous étiez fous, soldats, et la maladie n'avait pas attaqué avec plus de violence mon corps que vos esprits. 4 J'ai horreur de rapporter ce qu'on a cru, ce qu'on a espéré, ce qu'on a souhaité : que l'oubli emporte tout cela et l'anéantisse, s'il se peut; sinon, qu'en tout cas le silence l'ensevelisse ! 5 Je ne saurais dire que mon discours ne vous a pas semblé funeste et affreux: mais combien croyez-vous vos actions plus affreuses que mes paroles? Ce que vous avez fait, vous trouvez juste que je le supporte; et vous, vous ne souffrez pas, sans impatience, qu'on le raconte seulement? Pourtant, on arrêtera ici ces reproches mêmes. 6 Puissiez-vous oublier vous-mêmes votre conduite aussi facilement que moi je l'oublierai ! 7 Ainsi, pour ce qui vous concerne tous, si vous vous repentez de votre égarement, je vous trouve assez et trop punis. Pour Albius de Calès, et Atrius l'Ombrien, et les autres instigateurs d'une révolte sacrilège, ils laveront de leur sang la faute commise ; 8 vous, vous devez voir leur supplice non seulement sans peine, mais avec joie, si la raison vous est revenue : car c'était contre vous, plus que contre personne qu'ils avaient des desseins hostiles et méchants. »

3 Insanistis profecto, milites, nec maior in corpus meum vis morbi quam in vestras mentes invasit. 4 Horret animus referre quid crediderint homines, quid speraverint, quid optaverint : auferat omnia inrita oblivio, si potest; si non, utcumque silentium tegat. 5 Non negaverim tristem atrocemque vobis visam orationem meam : quanto creditis facta vestra atrociora esse quam dicta mea? Et me ea quae fecistis pati aequum censetis; vos ne dici quidem omnia aequo animo fertis? Sed ne ea quidem ipsa ultra exprobrabuntur. 6 Vtinam tam facile vos obliviscamini eorum quam ego obliviscar! 7 Itaque quod ad universos vos attinet, si erroris paenitet, satis superque poenarum habeo. Albius Calenus et Atrius Vmber et ceteri nefariae seditionis auctores sanguine luent quod admiserunt. 8 Vobis supplicii eorum spectaculum non modo non acerbum, sed laetum etiam, si sana mens rediit, debet esse : de nullis enim quam de vobis infestius aut inimicius consuluerunt. »

"Assurément, vous étiez fous, soldats »: c'est donc avec ces mots que débute la péroraison selon tous les commentateurs, à l'exception de Ferrazzi. Pour ce dernier, il s'agit de la conclusion de ce qui précède et non du début de la conclusion générale (" conclusio universalis»), qui commence donc selon lui au paragraphe 29, 4, "J'ai horreur...» Quel que soit le découpage pratiqué ici, dans ces dernières lignes, Scipion appelle d'abord à jeter le voile de l'oubli et du silence sur l'horrible produit d'un délire collectif dont il ne veut plus faire mention $(29,4)$. Dans une prolepse $(29,5)$, il anticipe la réaction des auditeurs face à la sévérité de son discours, mais les renvoie par « et vous?» ("uos ne ») au caractère intolérable de leurs actes. Puis il revient aussitôt à la clémence $(29,6)$. Toutefois, pour que l'oubli tant souhaité soit possible, il faut accomplir une dernière étape, il faut un châtiment. Scipion annonce sa sentence $(29,7):$ le pardon pour la masse, à condition qu'elle regrette, mais le supplice expiatoire pour les meneurs. Dans un ultime mouvement, Scipion use du paradoxe et inverse la direction $\mathrm{du}$ ressentiment pour inciter les hommes de troupe à abandonner leurs chefs : une saine pensée doit désormais voir dans le spectacle de l'exécution un motif de réjouissance, car ce sont les responsables de l'insurrection qui ont causé le plus de tort à ceux qui les ont suivis. 


\section{Tite-Live : synthèse des commentateurs}

Après cette lecture suivie, examinons de façon plus globale les preuves utilisées par Scipion. Cela nous permettra d'intégrer le commentaire de Junius, lequel est plus synthétique qu'analytique.

En ce qui concerne le logos, Ferrazzi relève donc les lieux ab adiunctis, a causis, a comparatione et ab effectis : Scipion s'appuie sur de nombreux exemples, souvent pour mettre en évidence des différences qui alourdissent la faute commise par ses hommes, il insiste sur les circonstances aggravantes intrinsèquement liées à la sédition, sur ses conséquences et détruit toutes les raisons qui auraient pu motiver ce soulèvement. Il redéfinit aussi sans cesse le crime. Tesmar divise quant à lui le discours en fonction des chefs d'accusation, des valeurs et interdits qui ont été transgressés.

Pour l'ethos, Ferrazzi reprend à Tesmar sa formule: celle d'un «dux clemens et severus ». L'orateur Scipion est un homme à la fois dur et conciliant, mais aussi un chef qui jouit par définition de la «majesté » ou souveraineté dans la décision, la maiestas. Notons que ce couplage de la clémence et de la sévérité annonce d'emblée le problème qui nous occupe. C'est déjà une indication sur le type de discours, ou si l'on préfère l'hésitation entre deux tons, la violence du chef sévère renvoyant à l'exprobratio, et la clémence, à l' obiurgatio. D'un côté, la condamnation sans appel ; de l'autre, l'objurgation à s'amender.

Au niveau du pathos, Scipion affiche de la colère, de la déception, de l'indignation aussi face aux exactions perpétrées par ses hommes. Mais il cherche également à susciter des émotions chez son public: Tesmar et Ferrazzi relèvent la peur (metus) du châtiment à venir et la honte (pudor) d'être pris en défaut d'un comportement attendu et d'une certaine image de soi. Le «et » qui relie honte et peur renvoie à un balancement du même ordre que celui entre sévérité et clémence. Les soldats ont peur du châtiment, mais la honte, en menant au retour sur soi et au repentir, prépare les voies de la clémence $(29,7$ : si et seulement "si vous vous repentez de votre égarement", "si erroris paenitet »).

L'analyse de Junius est quelque peu différente des deux précédentes, mais tout à fait complémentaire. Il relève sept arguments qui prouvent, ou "rationes probantes» : 1) les soldats n'avaient aucune raison de se rebeller : le chef ne s'est pas mal comporté envers eux; 2) à l'atrocité du crime lui-même sont attachées plusieurs circonstances aggravantes : les rebelles ont trahi leur chef, leur patrie, leur famille, leurs serments...; 3) ils ont transmis les insignes du pouvoir à des hommes de basse condition ; 4) ils n'ont pas pu accomplir leur geste pour trouver un nouveau lieu d'installation ou pour d'autres raisons; 5) le chef qu'ils ont abandonné n'est pas un inconnu dépourvu d'autorité : c'est le consul commandant les armées d'Espagne, qui a déjà remporté de nombreux succès éclatants, et contre lequel ils n'avaient aucune chance ; 6) les insurgés ont pris les armes contre leur propre patrie et contre les leurs, pour un objectif qui ne leur est absolument pas comparable ; 7) ils n'avaient pas le même motif de rébellion que Coriolan, à savoir une faute commise par Rome envers eux. Junius compte ensuite cinq arguments qui réfutent, ou "rationes refutantes » : 1) même si la mutinerie est due au furor de quelques-uns, la folie s'est étendue à tous et exige de grandes expiations ; 2) il était stupide de penser que si Scipion mourait, l'État disparaîtrait avec lui : d'autres sont morts avant lui, parfois en exerçant les mêmes fonctions, et ont été remplacés ; 3) le versement n'a été retardé que de quelques jours, à cause de la maladie de Scipion ; 4) 
ce léger retard ne pouvait en aucun cas justifier une réaction si disproportionnée ${ }^{16}$;5) ce qui s'est produit résulte en définitive d'un pur accès de folie.

Pour le logos donc, la lecture de Junius offre une vue d'ensemble assez équilibrée entre une volonté d'accabler les coupables et de les comprendre afin d'empêcher toute réplique ; Scipion décortique les motifs supposés de ses hommes et y répond, il concède pour mieux réfuter : cela est particulièrement visible sur le dernier point, le versement de solde, qui constitue le principal grief des insurgés ${ }^{17}$ et qui reçoit une double contreargumentation. À cela se mêle une série de lieux communs ${ }^{18}$ : sur la gravité d'une sédition, sur la basse extraction des meneurs, sur la modération, sur le retard du versement et ses causes.

Au niveau de l'ethos et du pathos, Junius a été particulièrement sensible à une dimension qui n'apparait que sporadiquement chez Tesmar et Ferrazzi : le désir de conciliation de Scipion, qui veut rassurer ses hommes, montrer qu'il est l'un des leurs, donner un peu d'espoir et raviver l'amitié ou benevolentia envers lui. En somme, c'est ce que Tesmar et Ferrazzi nomment de façon synthétique la clémence du chef. Junius décèle un ethos qui suscite l'amitié, ou "mores amabiles", à plusieurs points du discours: dans le discernement de Scipion qui refuse d'étendre la faute à tous; dans sa volonté de surseoir à de plus longs reproches et la promesse de ne plus y revenir; enfin, dans sa manière d'éviter d'attirer l'attention sur ses propres qualités et de s'effacer volontiers ${ }^{19}$ devant des intérêts ou valeurs supérieurs (patrie, survie de l'État). Selon Junius, le pathos ou émotion suscitée (motus) est donc l'amor, l'amitié voire l'amour, lorsque Scipion affirme préférer mourir plutôt que commander une armée qui en veut à sa vie.

31 En rassemblant les éléments mis en évidence dans les différentes analyses du discours, on peut retenir des traits saillants qui vont permettre d'aborder la question du genre, du type de discours. On voit en effet se dessiner deux lectures et deux compréhensions possibles de ce discours précis, qui se superposent et se complètent. Une première lecture, classique et linéaire, consiste à identifier deux parties dans l'argumentation de Scipion, qui correspondent exactement au passage d'un «chapitre » à un autre, soit de 27 à 28 - la division de Tite-Live en chapitres est contemporaine de nos commentateurs $^{20}$. Dans un premier temps (27), l'orateur condamne les faits et alourdit leur gravité en faisant appel à des valeurs, à des symboles et au-delà à une image idéalisée du soldat de la République. Dans un second temps (28), il tente de cerner le but de l'opération, de déterminer quel profit il y avait à en tirer. On retrouve là deux orientations majeures d'un discours délibératif, l'honorable et l'utile, honestum et utile $e^{21}$. Cependant, il paraît tout aussi sensé d'aborder ce discours sous l'angle judiciaire: d'abord Scipion accuse, montre en quoi l'action des soldats est condamnable et répréhensible; ensuite, il cherche les motifs ou les mobiles, évalue l'opportunité, les moyens à disposition, les conséquences probables, la préméditation de l'acte ${ }^{22}$. C'est cette seconde classification, judiciaire et non délibérative, qui a été unanimement privilégiée par les commentateurs cités. La répartition en deux temps reste d'ailleurs la même. Pour reprendre la métaphore médicale employée par Scipion ${ }^{23}$, après avoir tenté de qualifier le mal, il faut aussi en trouver l'origine afin de trouver le remède ; car il ne faut pas perdre de vue que l'objectif est bien la guérison.

Mais, pour le problème qui nous occupe, déterminer le type de discours, le choix entre judiciaire et délibératif reste encore trop général. Nous nous rapprocherons d'un type plus précis, l'exprobratio, quand nous remarquerons que le mot même exprobrare se trouve dans la bouche de Scipion, dans sa conclusion: " Pourtant, on arrêtera ici ces 
reproches mêmes [Sed ne ea quidem ipsa ultra exprobrabuntur]. 6 Puissiez-vous oublier vous-mêmes votre conduite aussi facilement que moi je l'oublierai !» Le mot se trouve à l'articulation même entre sévérité et clémence. Sa place conclusive invite à une autre lecture transversale du discours.

Cette lecture permet de remarquer qu'à côté du reproche sévère et accablant (exprobrare), le général diffuse en alternance un message plus rassurant, fait des concessions (mitigare, excusare, lenire), cherche un juste milieu pour ne pas dépasser la mesure ${ }^{24}$. Cette double composante se retrouve à tous les niveaux de l'argumentation de Scipion. Il se présente comme un dux clemens " et " severus, clément mais sévère, sévère mais clément. Il mêle des émotions positives et négatives (metus, pudor, amor), et, en proposant sa propre explication au mal qui a envahi l'armée, il ouvre la possibilité d'une résolution conditionnée. Ses analogies avec les mouvements de la mer et la maladie autorisent la clémence, mais elles désignent aussi des instigateurs; inversement, les analogies avec le sacrilège et le crime imposent quant à elles l'idée d'un sacrifice expiatoire. Rappelons enfin que la division entre ces deux orientations, sévérité et clémence, est particulièrement nette, voire brutale, chez Polybe. Cet autre aspect du discours constitue donc aussi une caractéristique majeure qui pourrait être pertinente pour la détermination du genre précis dont il relève.

\section{Objurgation ou reproches sévères ? L'apport des traités}

Les commentateurs qui ont été cités jusqu'à présent qualifient l'acte de Scipion de la manière suivante. Ferrazzi utilise le terme castigare, "châtier »; Tesmar emploie le même verbe et classe le discours parmi le genre judiciaire, les "orationes iudiciales"; Junius décrit le discours comme la "répréhension d'une sédition", "reprehensio seditionis » et dans son commentaire choisit le verbe obiurgare. Enfin, Perion hésite entre exprobratio et obiurgatio, et c'est sa formule que nous avons mise à notre titre, " obiurgatio siue exprobratio ", " une objurgation ou si l'on préfère des reproches sévères (une condamnation sans appel)». L'hésitation marquée par le siue de Perion est le problème fondamental, qui renvoie en première analyse à la structure binaire du discours, à la propre hésitation de Scipion entre clémence ou sévérité.

Tous ces termes ou verbes des commentateurs renvoient à des types précis de discours, appartenant au genre judiciaire, comme le confirment les traités de rhétorique de Vossius, Caussin ou Pelletier. Vossius définit l'objurgatio de la manière suivante ${ }^{25}$ :

OBJURGATION. C'est un reproche à cause d'un manquement au devoir, mais un reproche qui se propose d'amender autrui. L'objurgation se distingue donc de l'invective. L'invective ne s'adresse pratiquement qu'à des ennemis, et son but est de leur nuire ; l'objurgation, à des amis, avec pour visée de leur être utile. Une autre différence est que l'objurgation est en général dans la bouche du supérieur: le général y tance le soldat; le père, le fils.

OBJURGATIO est reprehensio ob delictum, quae emendationem alterius sibi proponat. Differt ab invectiva, quod haec fere circa inimicos versetur, \& id spectet, ut noceat; illa instituatur \& hoc studeat, ut prosit. Adde quod objurgatio plurimum est superioris; ut Imperatoris erga militem, patris adversus filium.

On retrouve sans peine les éléments du discours de Scipion. L'obiurgatio est un discours de reproche pour une faute commise (un « délit» ou delictum), mais elle a pour but de corriger et s'adresse à des personnes dont on espère encore quelque chose ; ce reproche 
émane toujours d'une personne qui jouit d'une position supérieure, d'une auctoritas. Correction ou répréhension disent la même chose que le verbe castigare, "châtier ", lequel semble recouvrir la même notion chez Ferrazzi et Tesmar ${ }^{26}$ : qui aime bien châtie bien. Pour en rester à Vossius, celui-ci, dans les chapitres qu'il consacre à ce type de discours qu'est l'obiurgatio, énumère toute une série de recommandations supplémentaires $^{27}$. Il faut d'abord exhiber le crime, le mettre sous les yeux, puis l'amplifier par exaggeratio en précisant tout ce qui a été bafoué ou toutes les entités qui ont été offensées du fait même du crime, en se servant des circonstances ou adiuncta. C'est le début du discours de Scipion. Ensuite, d'autres techniques visent à apaiser ou à émouvoir le public : il faut tempérer ses reproches, montrer que l'on souffre, que l'on agit à contrecœur (gr. prospoiêsis anagkês; lat. simulatio necessitatis), faire intervenir le sentiment des autres, faire appel à l'ancienne vertu et surtout, laisser entrevoir au destinataire l'espoir qu'il va s'amender, "spes emendationis ». Inversement, l'invectiva et l'exprobratio ${ }^{28}$ sont des formes de reproche particulièrement violentes, qui ne laissent guère de place pour la réplique et confinent à la rupture ; elles s'adressent plutôt à ceux que l'on considère comme des ennemis.

On trouve de semblables réflexions chez Caussin ou Pelletier à propos de l'obiurgatio ${ }^{29}$. Tous deux insistent lourdement sur la volonté d'apaisement, qui fait la spécificité de l' obiurgatio par rapport à l'invective : pour que le discours soit efficace, il faut se faire aimer et montrer que l'on aime, que c'est par amour que l'on agit, que l'on a été blessé et que l'on voudrait que les choses reprennent leur état antérieur. Ils apportent aussi par endroits des indications supplémentaires. L'exhibition de la faute dans toute son horreur, l'amplification par les circonstances aggravantes et les exemples, tiennent lieu de narration ; il n'est pas nécessaire de raconter le crime, qui ne fait pas question, mais de le rappeler, de le mettre sous les yeux « en recourant à une hypotypose " («per hypotyposim »), de mettre en lumière les aspects qui permettent de le qualifier et qui sont matière à reproche. C'est exactement ce que fait Scipion dans les brefs passages narratifs du discours : les énumérations et les exempla. Nous retrouvons par ce biais la narratio, dont nous avions dit en commençant qu'aucun des commentateurs ne la mentionnait. Pelletier, qui s'appuie justement sur ce discours de Scipion, donne des recommandations qui en sont directement inspirées: chercher les causes du crime, pour montrer qu'elles sont honteuses, légères ou contradictoires; trouver des exemples qui feront paraître le crime plus odieux encore, mêler les propos sévères et les menaces au pardon et aux appels à l'amendement.

Enfin, nous pouvons confirmer les remarques théoriques de Vossius, Caussin ou Pelletier en examinant les qualifications choisies par les auteurs de conciones, ainsi que les nombreux exemples commentés dans les traités de rhétorique. Un tel examen permet d'établir une liste de discours plus ou moins proches de celui de Scipion et regroupés sous une même étiquette ${ }^{30}$. J'en donnerai ici un aperçu non exhaustif.

Un de ces cas parallèles revient plus souvent que les autres dans les sources que j'ai exploitées jusqu'ici : le second discours de Germanicus au début des Annales de Tacite (I,

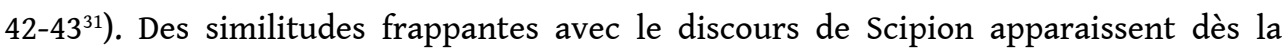
première lecture. Au niveau du récit tout d'abord, Germanicus doit faire face à une mutinerie telle que sa vie est menacée et qu'il est contraint de mettre son épouse et ses enfants en sécurité chez les Trévires. Ce spectacle désolant émeut un instant les soldats séditieux, moment dont profite Germanicus pour les infléchir; l'insurrection se termine dans le sang : les repentants se retournent spontanément contre leurs anciens 
meneurs. Dans le discours lui-même, on relève à nouveau les lieux $a b$ adiunctis, $a b$ effectis, a comparatione et exempla, et le sentiment de honte que le général tente d'inspirer à ses hommes, l'incompréhension, l'humilité, la modération. On retrouve également la posture qui consiste à s'effacer devant des intérêts supérieurs, celle qui consiste à préférer mourir plutôt que de subir un si triste spectacle, la figure d'invective, l'appel final à la conversion. Mais toutes ces ressemblances font aussi apparaître des différences sur les mêmes points.

D'une part, au niveau pragmatique et contextuel, Scipion et Germanicus ne sont pas exactement dans la même situation. Scipion dirige une sorte de procès, où l'orateur est à la fois juge et accusateur : le général romain a déjà repris les choses en main; il n'a dès lors plus besoin de convaincre, mais simplement de rendre la sentence, qu'il énonce à la fin du discours, plus acceptable ${ }^{32}$ aux yeux de la majorité afin qu'elle lui renouvelle sa loyauté. Germanicus profite quant à lui d'un signe de faiblesse dans la détermination des rebelles pour parvenir à les retourner. D'autre part, dans la forme du discours, l'intervention de Scipion débute par l'invective, et ce procédé est particulièrement développé, puisque Scipion hésite même à affubler ses hommes du terme hostes, en usant d'une distinction entre les apparences et la réalité33. Ce n'est qu'ensuite que Scipion envisage son point de vue personnel, qu'il exploite comme un moyen de reproche autant que pour susciter l'émotion. Les reproches sévères de Scipion montent constamment en puissance au point de retirer toute logique à l'insurrection de ses hommes, mais c'est en même temps de cette manière qu'il parvient à étayer une séduisante fiction, celle d'une folie passagère, que les auditeurs s'empresseront d'accepter en même temps que la condamnation de leurs meneurs.

Cette violence du ton est sans doute ce qui a fait hésiter Perion entre obiurgatio et exprobratio. Sous cette seconde étiquette, on trouve notamment chez lui la supplique du vieil Horace (Liv. I, 26, 10-11), qui s'indigne du fait que l'on s'apprête à le priver de son héros de fils en le récompensant par un châtiment (locus a contrariis). Ce sont aussi les paroles très dures de Véturie (Liv. II, 40, 5-9), qui ne sait plus si elle doit voir en Coriolan un fils ou un ennemi, alors que ce dernier s'apprête à ravager sa propre patrie et la maison qui l'a vu naître (locus ab effectis) : la traîtrise de Coriolan est pour elle un tel malheur qu'elle n'attend plus rien de la vie. Ces deux discours sont les ultimes cris de colère de ceux qui n'auront bientôt plus rien à perdre et qui appellent avant tout à la pitié. En revanche, toujours selon Perion, l'obiurgatio est, plus que le simple reproche, un appel à l'apaisement, à la raison, au respect des valeurs, qui doit précéder l'action ou la prise de décision. C'est l'objectif poursuivi par le consul Cincinnatus devant le Sénat (Liv. III, 21, 4-7), par Camille face au maître de Faléries (Liv. V, 27, 5-7), par Aristaenus interpellant l'assemblée des Grecs (Liv. XXXII, 20, 3-6). Un autre cas exemplaire d' obiurgatio est le discours du père à son fils, comme le discours du roi Philippe à Persée et Démétrius (Liv. XL, 8, 7-20) qui s'accusent mutuellement devant lui, discours dans lequel on trouve à nouveau bon nombre des lieux et procédés rhétoriques utilisés par Scipion. On comparera aussi au discours étudié l'objurgation adressée par Hannibal (Liv. XXIII, 45, 6-10) et Marcellus (Liv. XXVII, 13, 2-7) à leurs troupes respectives pour leurs piètres performances au combat: le premier ne reconnaît plus les grands vainqueurs de la Trébie, du lac Trasimène et de Cannes (locus ab antecedentibus); le second exploite davantage les conséquences (locus ab effectis) de l'échec.

Enfin, nous avons vu que Junius faisait du discours de Scipion la «répréhension d'une sédition ». Sous la même rubrique, "reprehensio seditionis", il mentionne, à côté du 
discours de Germanicus, une allocution d'Othon (Tac., Hist. I, 83-84) à ses troupes qui ont assassiné leurs officiers et semé le trouble dans Rome. Je retiendrai en particulier de ce discours l'habile résolution proposée par l'empereur: celui-ci interprète le désordre comme un excès de zèle et $d$ 'affection à son égard; cette énergie doit désormais être canalisée par la discipline et tournée contre Vitellius.

La mise en série permet donc de constater qu'un certain nombre de traits observés dans le discours de Scipion sont des éléments habituels, des régularités. Celles-ci dessinent les contours d'un genre. Les lieux employés sont en nombre limité et servent essentiellement à amplifier la faute en étudiant ses différents aspects, mais à côté du reproche, ou simultanément, l'orateur doit proposer une explication et un remède à la crise. Ce dernier se présente généralement comme un chef ou une personne qui jouit d'un ascendant sur l'auditoire, il doit se montrer à la fois sévère et clément ou bienveillant. Au niveau de l'émotion, c'est le sentiment de honte, éminemment social ${ }^{34}$, qui domine. On retrouve même, à travers les différents exemples, certaines figures ou postures rhétoriques, comme l'apostrophe, la désillusion, le désir de mort, qui apportent de l'intensité à certaines parties du discours et deviennent typiques.

Mais ces règles ne sont pas pour autant des normes: l'auteur peut choisir de les exploiter ou non, ou de les revisiter. Ainsi, le discours de Scipion prolonge l'interpellation initiale aux soldats, développe de façon originale des analogies avec la maladie, les mouvements de la mer, les sacrilèges à expier. Il analyse davantage les causes, progresse par concessions successives, qui sont convergentes avec une volonté d'effacement et de modestie chez le général, qui affiche ainsi une grande maîtrise de soi. Replacé au sein d'un nombre restreint de textes similaires, ce discours précis apparaît aussi sous un autre jour. Loin d'être une chimère rhétorique, un monstre protéiforme, fait de pièces disparates et pour une occasion singulière, il est plutôt un archétype rassemblant une série d'arguments et de techniques qui, associées de façon cohérente, déterminent un type de discours complexe, l'obiurgatio. Celle-ci consiste à réprimander sans dépasser la mesure sous peine de s'aliéner définitivement un interlocuteur que l'on considère comme un ami et dont on espère encore quelque chose.

C'est sans doute ce paramètre «transgénérique » qui engendre des types mixtes, au niveau des parties du discours et de leur contenu, et les rend particulièrement aptes à brouiller les frontières, d'ailleurs non étanches, entre les genres ou types de discours. L'hésitation de Perion quant à la qualification de ce discours précis nous rappelle aussi que c'est un équilibre précaire, car l'obiurgatio entretient par définition un lien étroit avec d'autres genres: à chaque nouveau reproche, en se montrant trop sévère, l'orateur court le risque de basculer dans l'hostilité foncière, l'exprobratio voire l'invective. Au lecteur d'apprécier si le discours de Tite-Live parvient effectivement à éviter cet écueil. Il reconnaîtra en tout cas que c'est une tâche délicate pour l'orateur qui se trouve dans une telle situation de la jauger correctement pour trouver les mots adéquats, de savoir où se trouve la limite floue à ne pas franchir et de trouver le bon dosage entre la fermeté et la conciliation. Cet art, pour Caussin et Pelletier, nécessite une compétence insigne, qui est l'intelligence politique, la "prudence», "artisan de l'éloquence » : « prudentia, artifex eloquentiae ». 


\section{NOTES}

1. Voir notamment les reconstructions proposées par H. H. Scullard, Scipio Africanus: Soldier and Politician, Ithaca (New York), Cornell UP, 1970 ; S. G. Chrissanthos, «Scipio and the Mutiny at Sucro, 206 B. C.», Historia 46, 2, 1997, p. 172-184 ; E. T. Salmon, «Scipio in Spain and the Sucro Incident », StudClas 24, 1986, p. 77-84.

2. On pense immédiatement à l'exhortatio militaire, élément incontournable du récit de bataille, mais grande oubliée des traités antiques (voir sur ce point la réflexion entamée par Francis Goyet, "Le problème de la typologie des discours ", Exercices de rhétorique, 1| 2013, URL http:// rhetorique.revues.org/122). On trouvera une problématique comparable à celle du discours étudié ici dans l'analyse faite par Christine Noille du discours de Germanicus aux légions séditieuses : voir ici même dans ce numéro.

3. J'utiliserai ici les ouvrages suivants: Marco Antonio Ferrazzi, Exercitationes rhetoricae in orationes Titi Livii Patavini, Padoue, J. Manfré, 1694, où c'est le discours n 111 (p. 184-188 dans l'éd. 1740 sur Google) ; Johannes Tesmar, Rhetoricarum exercitationum libri VIII, Amsterdam, Elzévir, 1657, p. 415 (Google ; discours $\mathrm{n}^{\circ}$ 138) ; Joachim Perion, In omnes T. Liuii Conciones (...), Bâle, Winter, 1545, p. 319-330 (BSB ; discours $\mathrm{n}^{\circ} 130$ - la formule reprise à mon titre est dans sa table : «Obiurgatio, siue exprobratio P. Scipionis in suos») ; Melchior Junius, Orationum ex historicis tam veteribus, quam recentioribus (...), Strasbourg, Zetzner, 1598, livre II, p. 227-230 (Google).

4. Je ferai uniquement référence aux ouvrages suivants : Gerhard J. Vossius, Rhetorices contractae, sive Partitionum Oratoriarum libri quinque, Leipzig, Kirchner, 1660 ( $1^{\text {re }}$ éd. Leyde, J. Maire, 1621) ; Nicolas Caussin, Eloquentiae Sacrae et Humanae Parallela, Paris, Chappelet, 1619 ; Gérard Pelletier,

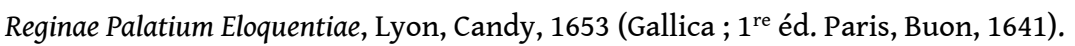

5. Voir notamment E. Burck, « Einzelinterpretationen von Reden » dans E. Burck (hrsg), Wege zu Livius, Darmstadt, Wissenschaftliche Buchgesellschaft, 1977 [1967], p. 430-463 et R. Ullmann, La technique des discours dans Salluste, Tite-Live et Tacite. La matière et la composition, Oslo, J. Dybwad, 1927.

6. Voir à ce propos : M. F. Williams, " "Shouldn't you have come and talked to me about it?" : Democracy and Mutiny in Scipio's Army (Polybius 11. 25-30)», The Ancient History Bulletin, 15, 4, 2001, p. 143-153.

7. Polybe XI, 25.

8. Voir également : Jean Le Deist de Botidoux, Conciones et discours choisis dans Salluste, Tite-Live, Tacite et Quinte-Curce, Paris, Libr. classique et d'éducation, 1823, p. 432 ; Antoine-Arthur Vauchelle, Conciones latinae e sacris necnon e profanis scriptoribus excerptae. Nouveau recueil, publié avec exposés historiques, plans et notes en français, Paris, Librairie Ch. Poussielgue, 1898 (3éd.), p. 147.

9. Nous reprenons le texte latin et la traduction française de Charles Nisard, Paris, Firmin-Didot, 1864 (sur Itinera Electronica).

10. J. Dangel, «Les structures de la phrase oratoire chez Tite-Live », Revue des Études latines, 54, 1976, p. 236.

11. Dans ce discours, Scipion compare le plus souvent des objets inégaux, avec une hiérarchie implicite. On parlerait donc dans une typologie moderne d'argument a fortiori (C. Perelman et L. Olbrechts-Tyteca, Traité de l'argumentation, Bruxelles, Université Libre de Bruxelles, 1958 [2008], p. 453-470).

12. Tesmar : "image tirée des blessures " (" similitudo a uulneribus »); Ferrazzi : «très belle allégorie» («pulcherrimam allegoriam»). Pour le second, cette image fait encore partie de l'argument précédent dans un bloc 27, 5-7. 
13. L'analyse rhétorique rencontre ici la philologie. Ferrazzi, Tesmar et Junius lisent quin au lieu de qui. Or, cette dernière leçon, qui, est celle adoptée par les éditions les plus récentes (par exemple R. S. Conway et S. K. Johnson, OCT, 1953 ; Paul Jal, CUF, 1995) : elles rattachent ainsi le paragraphe 27, 12 à ce qui suit plutôt qu'à ce qui précède, constituant ainsi un autre développement cohérent jusqu'au paragraphe 16. La leçon quin souligne à propos une gradation dans l'argumentation; la leçon qui offre moins de lisibilité au niveau de la division rhétorique et prolonge le développement jusqu'au paragraphe 27, 13, où Scipion entame un retour sur les événements en écartant sciemment ce qui concerne sa propre personne. Il semble que les éditeurs modernes aient privilégié dans leur présentation du discours les différents «pas de côté » effectués par le général et qui font également progresser sa pensée.

14. Je fais ici allusion à ce que la logique informelle appelle le practical reasoning et qui concerne essentiellement l'argumentation par le but et les conséquences (voir par exemple: D. N. Walton, Practical Reasoning. Goal-Driven, Knowledge-Based, Action-Guiding Argumentation, Savage, Maryland, Roman \& Littlefield, 1990).

15. 1) La causa formalis (une ville comme Rome n'est pas un corps mortel) ; 2) les antécédents ; 3) les exemples récents des Scipions ; 4) l'existence de successeurs potentiels ; 5) la cause finale avec l'exemple dissemblable de Coriolan.

16. Il s'agit de ce que le Traité de l'argumentation nomme un argument de direction (C. Perelman et L. Olbrechts-Tyteca, Traité, op. cit., p. 379-386).

17. Cf. Tite-Live, XXVIII, 25, 6.

18. Junius semble utiliser cette expression dans un sens quelque peu différent de Ferrazzi. Si l'on se réfère aux différents sens de "lieu commun» identifiés par Fr. Goyet (Le sublime du «lieu commun ». L'invention rhétorique dans l'Antiquité et à la Renaissance, Paris, Champion, 1996), Ferrazzi s'inspire directement des traités antiques et applique le sens III (schémas ou règles d'inférence valables dans tous les genres et types de causes) tandis que Junius se rapproche du sens I (développement oratoire plus ou moins figé, et, ici, pensées frappantes).

19. 27, 13 : «sur moi, je ne dirai rien » (« de me ipso taceo »);28, 8 : «Admettons cependant qu'eux aussi, vous les ayez chassés de vos cœurs, comme votre patrie et moi-même » (« sed horum quoque memoriam, sicut patriae meique, eieceritis ex animis uestris »);28, 10 : "j'écarte, je mets à part mon nom » (" amolior et amoueo nomen meum »).

20. Elle est due, en 1612, à Janus Grüter ou Jan de Gruytere (1560-1627), lequel est aussi l'auteur du découpage en chapitres de Tacite, en 1607, et de Cicéron, en 1618 (voir: H.-J. Martin, La naissance du livre moderne, mise en page et mise en texte du livre français (XIVe-XVII ${ }^{e}$ siècles), Paris, éd. du Cercle de la Librairie, 2000, p. 309). Le fait que Grüter isole un chapitre 29 signifie peut-être qu'il voit là, avec l'exemple dissemblable de Coriolan, le début de la péroraison. - Quant au découpage en paragraphes, il serait plus tardif : 1738, dans l'éd. Drakenborch de Tite-Live (selon R. S. Conway, dans sa propre édition de Tite-Live, OCT, 1953).

21. Cicéron, De Inv. II, 155-176; De Or. II, 333-361. Ce sont également les deux parties d'une conciliatio du second type chez Vossius (Rhet. Contr. II, 22, § 5, éd. 1660, p. 192 ; texte et trad. dans G. J. Vossius, Rhetorice contracta (1621), II, 22, «Les discours de sédition et d'union », Exercices de rhétorique, 1 | 2013, URL http://rhetorique.revues.org/170).

22. Cf. Cicéron, De Inv. I, 34-43 ; II, 14-115 ; De Or. II, 114-178 ; Part. 34-43 ; Top. ; Quintilien, Inst. or. $\mathrm{V}, 10$. Dans la seconde partie du discours d'ailleurs, à partir du chapitre 28 , Scipion utilise un vocabulaire judiciaire (" crime », « scelus » à $28,1,2$ et 8 , " acte sacrilège ", " res nefaria » à 28,1 et «nefaria » à 29,7 ), alors que dans la première partie le lexique est plus politique (« révolte », « seditio » à 29,7 , «forfait », «facinus » à $27,10,12,16$ et 28,3$)$.

23. On retrouve également cette métaphore chez Vossius pour la conciliatio (Rhet. Contr. II, 22, éd. 1660, p. 193, § 7 ; texte et trad. dans G. J. Vossius, Rhetorice contracta (1621), II, 22, « Les discours de sédition et d'union ", op. cit.). 
24. Cette préoccupation apparaît aussi dans le récit qui précède le discours : "Scipion, habitué aux campagnes <militaires>, mais peu fait aux orages des émeutes, s'inquiétait toujours, en cette affaire, que l'armée ne passât la mesure dans ses fautes, ou lui-même dans la répression » (Liv. XXVIII, 25, 8 : « Scipionem, bellis adsuetum, ad seditionum procellas rudem, sollicitum habebat res ne aut exercitus peccando aut ipse puniendo modum excederet $»)$.

25. Gerhard J. Vossius, Rhet. Contr. II, 26, p. 215 (vue 226) ; traduction proposée par Laurence Vianès (RARE).

26. Je m'appuie ici sur les travaux en cours de l'équipe RARE (cf. Compte-rendu de la réunion du 21 octobre 2011). Force est de constater que le verbe castigare est utilisé par Ferrazzi et Tesmar chaque fois que Perion définit le même discours comme une obiurgatio. Le verbe castigare est également lié à certaines harangues, comme celle d'Hannibal devant les Alpes (Liv. XXI, 30, 2-11). 27. Rhet. Contr. II, 26, éd. 1660, p. 215-219 (vues 226-230).

28. Pour l'invectiva, voir Rhet. Contr. II, 26, éd. 1660, p. 214-215 (vues 225-226). L'exprobratio, mentionnée par Perion, appartient aussi au genre judiciaire et s'oppose, dans le genre de la plainte, à l'expostulatio, plus modérée. Voir : Vossius, Rhet. Contr. II, 27, éd. 1660, p. 219-221, texte et trad. dans G. J. Vossius, Rhetorice contracta (1621), II, 27, « Les discours de reproches et de condamnation sans appel ", Exercices de rhétorique, 2 | 2013, URL http://rhetorique.revues.org/ 190 ; Nicolas Caussin, Eloquentiae XII, 37, éd. 1619, p. 544-545 (vues 558-559).

29. Gérard Pelletier, Reginae, Ex. X, Punct. 4, éd. 1653, p. 866-870 (vues 874-878) ; Nicolas Caussin, Eloquentiae XII, 35, éd. 1619, p. 543-544 (vues 558-559).

30. Dans les sections qu'ils consacrent respectivement à l'obiurgatio, Caussin donne comme exemple le discours de Germanicus chez Tacite (que nous analysons ensuite) ; Vossius y ajoute le discours de Véturie (Liv. II, 40, 5-9) ; Pelletier cite entre autres, outre le discours de Germanicus, celui du vieil Horace (Liv. I, 26, 10-11), un discours d'Aristaenus (Liv. XXXII, 20, 3-6), et, de Cicéron, les Catilinaires et le Pour le roi Déjotarus. Les autres exemples ont été obtenus grâce aux étiquettes fournies par Perion et aux ressources informatisées de l'équipe RARE.

31. Pour reprendre l'analyse de ce discours par Christine Noille, le type du discours de Tacite n'est lui-même pas clair : Pelletier y voit une conciliatio, Vossius une obiurgatio et le récit de Tacite commente le discours avec le verbe exprobrare. Voir également, sur la façon dont Pelletier analyse ce discours de Germanicus, la note 28 de Fr. Goyet à G. J. Vossius, Rhetorice contracta (1621), II, 22, "Les discours de sédition et d'union », op. cit.

32. La décision de Scipion a été mûrement réfléchie et se veut clémente, ainsi que l'indique TiteLive lui-même dans le récit qui précède le discours: "L'avis le plus doux l'emporta: aux instigateurs de la faute on limiterait le châtiment; à l'égard de la masse, une réprimande [castigatio] suffirait» (Liv. XXVIII, 26, 3: "vicit sententia lenior ut unde culpa orta esset ibi poena consisteret: ad multitudinem castigationem satis esse »). Il faut ici se départir de nos conceptions modernes. Scipion aurait pu ordonner une exécution plus massive, notamment en décimant l'armée : ce serait là la sévérité, une justice appliquée en toute rigueur. Mais il fait preuve de maîtrise : la clémence suppose la réparation (en l'occurrence, le châtiment), elle ne l'empêche pas.

33. C. Perelman et L. Olbrechts-Tyteca, Traité, op. cit., p. 556-568.

34. Voir à ce propos R. Micheli, L'émotion argumentée. L'abolition de la peine de mort dans le débat parlementaire français, Paris, Cerf (coll. « Humanités »), 2010, p. 439-453. 


\section{AUTEUR}

\section{BENOITT SANS}

Université Libre de Bruxelles - G.R.A.L. 